\title{
Cancer occurrence in a cohort of patients surgically treated for peptic ulcer
}

\author{
H Møller, C Toftgaard
}

\begin{abstract}
A cohort of 4107 patients treated surgically for peptic ulcer between 1955 and 1960 was followed up to determine the incidence of cancer by record linkage to the Danish Cancer Registry. A total of $\mathbf{9 3 0}$ cases of cancer were observed during 76634 person-years. Relative risks of cancer were computed by comparison with the recorded cancer incidence in the Danish population. During the first five years after surgery the relative risk of gastric cancer was slightly increased ( $R R=1.43$ ), but 5-15 years after the operation the risk was lower than expected $(\mathbf{R}=\mathbf{0}=\mathbf{5 5})$. Thereafter, the relative risk of gastric cancer increased steadily and increased more than twofold after 25 years. Lung cancer occurred more frequently in the cohort members than expected $(R R=1 \cdot 66)$, but the relative risk was independent of time since surgery. Malignancies other than gastric cancer and cancers related to tobacco smoking were close to the expected numbers. The results do not support the findings of a recent British study of similar size in which increased risks were reported for cancer at other sites.
\end{abstract}

The occurrence of gastric carcinomas in patients previously treated surgically for peptic ulcer has been the subject of several epidemiological cohort studies. ${ }^{1}$ Few of these studies have, however, been of sufficient size to arrive at firm conclusions regarding the magnitude of the subsequent risk of cancer. It is now becoming clear that the latency time of the process of carcinogenesis must be taken into account in the analysis of such cohort studies because the diagnosis and surgical treatment for peptic ulcer itself constitutes effective 'screening' for gastric cancer. Since a part of the stomach was actually removed in the majority of cases (before the successful introduction of medical treatment in the 1970s), the risk of gastric cancer secondary to surgical treatment for ulcer may depend heavily on the span of time elapsed since the operation.

Several large studies of white populations have recently been published. Viste et al in Norway followed a cohort of 3470 patients. ${ }^{2}$ The relative risk of gastric cancer incidence in this cohort was near the expected in the years immediately after operation but increased gradually with time, and 21-40 years after treatment for peptic ulcer the relative risk was $3.9(p<0.001)$. Lundegårdh et $a l$, in a large study of 6459 Swedish patients, similarly found a gradually increasing relative risk of gastric cancer incidence after surgery, ${ }^{3}$ and the relative risk was significantly increased after a latency period of 25 years. In Iceland, Arnthorsson et al again reported this pattern of gastric cancer incidence in a cohort of 1795 ulcer patients. ${ }^{4}$ In this study the relative risk of gastric cancer 0-14 years after surgery was significantly below the expected $(R R=0 \cdot 49 ; 95 \%$ confidence interval 0.24 to 0.90 ), but after 15 years the relative risk was significantly increased $(R R=$ $2 \cdot 17 ; 95 \%$ CI $1 \cdot 46$ to $3 \cdot 10$ ).

Caygill et al followed up 4514 patients for cancer mortality in Britain. ${ }^{5-8}$ For gastric cancer mortality a relative risk of $4.5(\mathrm{p}<0.001)$ was observed 20 years or more after the operation for peptic ulcer. Furthermore, increased relative risks were observed for cancer of the colon and rectum, biliary tract, female breast, pancreas, oesophagus, bladder, and lung. The relative risks were below or near the expected in the first 20 years. The findings of Caygill et al were interpreted as evidence for the production of circulating carcinogens in the gastric stump. After surgery for peptic ulcer the reduced acidity may allow colonisation of nitrate reducing bacteria, which could lead to increased endogenous formation of $N$-nitroso compounds, ${ }^{9}$ which may increase the risk of gastric cancer. Some compounds in this class of chemicals are locally acting carcinogens - for example, the $N$-nitrosamides - while others, such as the $N$-nitrosamines, require metabolic activation before the carcinogen is produced..$^{10}$ If $N$-nitrosamines or other carcinogens requiring metabolic activation are produced in the gastric stump, carcinogenesis could be enhanced at sites other than the stomach itself.

One of us (CT) has collected information on 4131 Danish ulcer patients. ${ }^{11-13}$ We have now extended the follow up of the cohort and replicated as close as possible the analyses published by Caygill $e t a l^{5}$ in order to provide an independent check of the conclusions of the British study of cancer at multiple sites after surgery for peptic ulcer.

\section{Methods}

The 4131 surgery reports of patients treated for peptic ulcer between 1955 and 1960 in the western part of Denmark were collected as described earlier. ${ }^{8-10}$ Cancer occurrence in this cohort through 1982 has been described previously. ${ }^{12}$ We have now followed up the cohort for a further five years.

The cohort was linked by means of the personal identification number, unique to every Danish citizen, by computer to the Danish Central Population Register, which holds a roster of the total Danish population, and to the Danish Cancer Registry, which since 1943 has recorded all cases of cancer in the Danish population. ${ }^{14}$ From the population register we extracted the vital status of the cohort members by 31 December 1987 and the date of death if this had

\author{
Department of Surgery, \\ Kjellerup Hospital, \\ C Toftgaard \\ Correspondence to: \\ Dr Møller. \\ Accepted for publication \\ 10 September 1990 \\ Danish Cancer Regitu \\ Epidemiology, D \\ Rosenvængets Hovedve \\ 35, PO Box 839 ,
}


occurred before this date. From the cancer registry we extracted information of all malignancies occurring in the cohort from the time of operation to 31 December 1987.

Person-years at risk were calculated from the date of peptic ulcer surgery to death, emigration, or 31 December 1987, whichever occurred first. Cancer occurrence in the cohort was compared with that in the Danish population as a whole, taking into account sex and age and period of risk (both in five-year intervals). Relative risks were estimated as the observed number of cases divided by the expected number, and one tailed statistical tests assumed the number of cases to follow a Poisson distribution.

Among the 4131 surgery reports, we were unable to obtain the vital status for 17 patients, and inconsistencies in the data appeared for seven patients, who were therefore excluded. The present analysis is thus confined to 4107 patients (Table I). Table II gives details of sex, diagnosis, and type of operation for the study cohort. Overall, 930 cases of cancer occurred in 4107 patients over 76634 person-years (Table III). Twenty years or more after peptic ulcer surgery 329 cases of cancer occurred in 2090 patients over 15878 person-years.

\section{Results}

In the first 20 years after operation for peptic ulcer the relative risk of cancer is raised ( $R R=$ $1.17 ; \mathrm{p}<0.001$ ) (Table IV). Significantly increased risks are observed for cancer of the lung, bladder, brain and nervous system, for leukaemia, and for metastatic cancer of unknown origin. The number of cases of gastric cancer in this cohort in the first 20 years after surgery is close to the expected $(R R=0.85)$.

Twenty years or more after operation the overall cancer risk is increased $(R R=1 \cdot 28$; $\mathrm{p}<0.001$ ), but significantly increased relative risks are now seen only for gastric cancer $(R R=1.80 ; p<0.01)$, lung cancer $(R R=1.80$; $\mathrm{p}<0.001)$, and non-Hodgkin lymphomas $(\mathrm{RR}=$ $2 \cdot 32 ; \mathrm{p}<0.05)$. Cancer incidence at all remaining sites is close to the expected. There were no cases of gastric lymphomas among the 10 cases of non-Hodgkin lymphomas.

The relative risk of cancer at all sites is given in Table $\mathrm{V}$ by diagnosis and by type of operation. There is no difference in cancer risk after gastric ulcer and duodenal ulcer, but patients with other diagnoses seem to be at even higher risk. Evaluation of cancer risk by type of operation is difficult because the great majority of patients in the cohort had had a Billroth II resection.

Table VI gives the occurrence of gastric cancer by diagnosis and by type of operation. There is no effect of diagnosis, and the fact that most of the patients had had a Billroth II resection again makes any conclusion regarding type of operation difficult. It may seem, however, that those who only had a simple suture for a perforated ulcer are at lower risk of gastric cancer than patients treated with other operations. The excess incidence of lung cancer in the cohort is spread evenly over diagnoses and types of operations (Table VII).

The published evidence from the British study
TABLE I Exclusions before analysis

Total surgery series

No information on date of death

Inconsistent data

Cohort for follow up

TABLE II Study cohort: age, initial diagnosis, type of operation, and age distribution within each subgroup

\begin{tabular}{lcll}
\hline & & \multicolumn{2}{l}{ Age (years) } \\
\cline { 3 - 4 } & No of & \\
\cline { 3 - 4 } & patients & Median & Quartile range \\
\hline Men & 3120 & 52 & $41-60$ \\
Women & 987 & 53 & $44-62$ \\
Diagnoses: & & 55 & $46-63$ \\
Gastric ulcer & 1222 & 55 & $41-59$ \\
Duodenal ulcer & 2560 & 51 & $38-57$ \\
Other & 325 & 49 & $42-60$ \\
Operation: & 2838 & 51 & $31-59$ \\
Billroth II & 445 & 51 & $38-60$ \\
Billroth I & 596 & 50 & $52-72$ \\
Simple suture & 228 & 63 & \\
Othert & &
\end{tabular}

^Includes combined gastric and duodenal ulcer, jejunal ulcer, and pyloric gastritis.

†Includes gastrojejunostomy (109), vagotomy with drainage (38), and various other operations $(81)$.

proposed certain subgroup analyses, especially for colorectal cancer, female breast cancer, and gall bladder cancer. ${ }^{58}$ Analyses are given in Table VIII. The Danish evidence supports none of these proposed associations.

The Figure shows in more detail the relative risk of cancer at all sites, of lung cancer, and of gastric cancer by latency time after operation for peptic ulcer. The incidence of cancer at all sites is raised at a level around $R R=1 \cdot 20$, and the incidence of lung cancer is generally raised at a level near $R R=1 \cdot 7$. The incidence of gastric cancer, however, shows a striking pattern. In the first five years after operation the risk is increased, but 5 to 15 years after operation the incidence of gastric cancer is only about half of the expected ( 12 cases; $R R=0.55 ; \mathrm{p}<0.05$ ). Fifteen years after operation the risk of gastric cancer begins to increase and the relative risk is increased more than twofold 25 years after surgery for the ulcer.

When we consider cancer at all sites excluding gastric cancer and cancers related to tobacco consumption (buccal cavity and pharynx, oesophagus, pancreas, larynx, lung, and bladder) the remaining number of observed cases in the first 20 years is $331(R R=1 \cdot 04 ; p=0 \cdot 23)$. Similarly, after 20 years of latency there are 180 cases and the relative risk is only slightly, and not significantly, increased $(R R=1 \cdot 12 ; p=0 \cdot 07)$.

\section{Discussion}

The pattern of gastric cancer occurrence in the present study is striking. In the first five years after operation for peptic ulcer the relative risk of gastric cancer is slightly increased (16 cases; $R R=1 \cdot 43 ; p=0 \cdot 10$ ). It is most likely that these patients already had gastric cancer at the time of operation, and in some cases the cancer may even have contributed to the symptoms which were interpreted and treated as benign peptic ulcer. The proportion of these 16 patients who had a diagnosis of gastric ulcer was greater than in the total cohort ( $56 \% v 30 \%$ ), and a smaller proportion had a Billroth I or II operation ( $44 \% v 80 \%$ ). 
TABLE III Number of patients and person-years, mean follow up, and number of observed cases of cancer in study cohort, by latency time after operation

\begin{tabular}{llllll}
\hline Sex & $\begin{array}{l}\text { Latency time } \\
\text { (years) }\end{array}$ & $\begin{array}{l}\text { No of subjects } \\
\text { entering interval }\end{array}$ & Person-years & $\begin{array}{l}\text { Mean follow up } \\
\text { (years) }\end{array}$ & $\begin{array}{l}\text { No of cases } \\
\text { of cancer }\end{array}$ \\
\hline Men & $0-19$ & 3120 & 46095 & $14 \cdot 8$ & 482 \\
Men & $20+$ & 1563 & 11714 & 7.5 & 264 \\
Women & $0-19$ & 987 & 14662 & $14 \cdot 8$ & 119 \\
Women & $20+$ & 527 & 4164 & 7.9 & 65 \\
Total & $0+$ & 4107 & 76634 & $18 \cdot 7$ & 930 \\
\hline
\end{tabular}

TABLE IV Number of cases and relative risk of cancer $(R R)$ at different sites, by latency time after operation

\begin{tabular}{|c|c|c|c|c|c|c|}
\hline & \multicolumn{6}{|c|}{ Latency time (years) } \\
\hline & \multicolumn{2}{|l|}{$0-19$} & \multicolumn{2}{|l|}{$20+$} & \multicolumn{2}{|l|}{ Total } \\
\hline & No of cases & $R R$ & No of cases & $R R$ & No of cases & $R R$ \\
\hline $\begin{array}{l}\text { All sites } \\
\text { Buccal cavity and }\end{array}$ & 601 & $1 \cdot 17 \ddagger$ & 329 & $1 \cdot 28 \ddagger$ & 930 & $1 \cdot 21 \ddagger$ \\
\hline $\begin{array}{l}\quad \text { pharynx } \\
\text { Oesophagus } \\
\text { Stomach } \\
\text { Colon } \\
\text { Rectum } \\
\text { Liver } \\
\text { Gall bladder } \\
\text { Pancreas } \\
\text { Larynx } \\
\text { Lung } \\
\text { Female breast } \\
\text { Female genital }\end{array}$ & $\begin{array}{r}16 \\
9 \\
36 \\
29 \\
36 \\
2 \\
8 \\
19 \\
9 \\
125 \\
21\end{array}$ & $\begin{array}{l}1.21 \\
1.49 \\
0.85 \\
0.75 \\
1.06 \\
0.44 \\
1.34 \\
1.05 \\
1.50 \\
1.59 \ddagger \\
0.88\end{array}$ & $\begin{array}{r}8 \\
3 \\
23 \\
27 \\
13 \\
3 \\
1 \\
13 \\
6 \\
77 \\
9\end{array}$ & $\begin{array}{l}1.43 \\
1.21 \\
1.80 \dagger \\
1.22 \\
0.92 \\
1.05 \\
0.39 \\
1.44 \\
1.97 \\
1.80 \ddagger \\
0.89\end{array}$ & $\begin{array}{r}24 \\
12 \\
59 \\
56 \\
49 \\
5 \\
9 \\
32 \\
15 \\
202 \\
30\end{array}$ & $\begin{array}{l}1.27 \\
1.41 \\
1.07 \\
0.92 \\
1.02 \\
0.68 \\
1.06 \\
1.18 \\
1.66^{\star} \\
1.66 \ddagger \\
0.89\end{array}$ \\
\hline $\begin{array}{l}\text { organs } \\
\text { Prostate } \\
\text { Kidney } \\
\text { Bladder } \\
\text { Non-melanoma }\end{array}$ & $\begin{array}{l}20 \\
48 \\
19 \\
56\end{array}$ & $\begin{array}{l}0.83 \\
1 \cdot 18 \\
1.23 \\
1.69 \ddagger\end{array}$ & $\begin{array}{r}8 \\
27 \\
9 \\
19\end{array}$ & $\begin{array}{l}1 \cdot 00 \\
1 \cdot 04 \\
1 \cdot 22 \\
1 \cdot 01\end{array}$ & $\begin{array}{l}28 \\
75 \\
28 \\
75\end{array}$ & $\begin{array}{l}0.87 \\
1.13 \\
1.22 \\
1.44 \dagger\end{array}$ \\
\hline $\begin{array}{l}\text { skin cancer } \\
\text { Brain and nervous }\end{array}$ & 52 & 1.07 & 39 & $1 \cdot 21$ & 91 & $1 \cdot 13$ \\
\hline $\begin{array}{l}\text { system } \\
\text { Metastases } \\
\text { Non-Hodgkin }\end{array}$ & $\begin{array}{l}19 \\
14\end{array}$ & $\begin{array}{l}1 \cdot 77^{\star} \\
1 \cdot 87^{\star}\end{array}$ & $\begin{array}{l}5 \\
4\end{array}$ & $\begin{array}{l}1 \cdot 29 \\
1 \cdot 13\end{array}$ & $\begin{array}{l}24 \\
18\end{array}$ & $\begin{array}{l}1 \cdot 64^{\star} \\
1 \cdot 64^{\star}\end{array}$ \\
\hline $\begin{array}{l}\text { lymphomas } \\
\text { Leukaemia }\end{array}$ & 21 & $\begin{array}{l}0.60 \\
1.56^{\star}\end{array}$ & $\begin{array}{r}10 \\
8\end{array}$ & $\begin{array}{l}2 \cdot 32^{\star} \\
1 \cdot 27\end{array}$ & $\begin{array}{l}15 \\
29\end{array}$ & $\begin{array}{l}1 \cdot 19 \\
1 \cdot 47^{\star}\end{array}$ \\
\hline
\end{tabular}

${ }^{\star} \mathrm{p}<0.05 ; \mathrm{t} \mathrm{p}<0.01 ; \neq \mathrm{p}<0.001$ (one sided $\mathrm{p}$ values).

TABLE V Number of cases and relative risk of cancer at all sites $(R R)$, by latency time after operation and by diagnosis and type of operation

\begin{tabular}{|c|c|c|c|c|}
\hline & \multicolumn{4}{|c|}{ Latency time (years) } \\
\hline & \multicolumn{2}{|l|}{$0-19$} & \multicolumn{2}{|l|}{$20+$} \\
\hline & $\begin{array}{l}\text { No of } \\
\text { cases }\end{array}$ & $R R$ & $\begin{array}{l}\text { No of } \\
\text { cases }\end{array}$ & $R R$ \\
\hline \multicolumn{5}{|l|}{ Diagnosis: } \\
\hline Gastic ulcer & 177 & 1.09 & 83 & $1 \cdot 21^{\star}$ \\
\hline Duodenal ulcer & 367 & $1 \cdot 18 \ddagger$ & 216 & $1 \cdot 29 \ddagger$ \\
\hline Other & 57 & $1.49 t$ & 30 & $1 \cdot 41^{\star}$ \\
\hline $\begin{array}{l}\text { Operation: } \\
\text { Billroth II }\end{array}$ & 429 & $1 \cdot 18 \ddagger$ & 241 & $1 \cdot 32 \ddagger$ \\
\hline Billroth I & $\begin{array}{r}427 \\
61\end{array}$ & $1 \cdot 10^{+}$ & $\begin{array}{r}2+1 \\
29\end{array}$ & $0.95+$ \\
\hline Simple suture & 80 & $1 \cdot 26^{\star}$ & 50 & $1 \cdot 39 \star$ \\
\hline Other & 31 & 0.97 & 9 & $1 \cdot 19$ \\
\hline Total & 601 & $1 \cdot 17 \ddagger$ & 329 & $1.28 \ddagger$ \\
\hline
\end{tabular}

${ }^{\star} \mathrm{p}<0.05 ; \mathrm{tp}<0.01 ; \ddagger \mathrm{p}<0.001$.

TABLE VI Number of cases and relative risk of gastric cancer $(R R)$, by latency time after operation and by diagnosis and type of operation

\begin{tabular}{|c|c|c|c|c|}
\hline & \multicolumn{4}{|c|}{ Latency time (years) } \\
\hline & \multicolumn{2}{|l|}{$0-19$} & \multicolumn{2}{|l|}{$20+$} \\
\hline & $\begin{array}{l}\text { No of } \\
\text { cases }\end{array}$ & $R R$ & $\begin{array}{l}\text { No of } \\
\text { cases }\end{array}$ & $R R$ \\
\hline \multirow{10}{*}{$\begin{array}{l}\text { Diagnosis: } \\
\text { Gastric ulcer } \\
\text { Duodenal ulcer } \\
\text { Other } \\
\text { Operation: } \\
\text { Billroth II } \\
\text { Billroth I } \\
\text { Simple suture } \\
\text { Other } \\
\text { Total }\end{array}$} & & & & \\
\hline & 15 & 1.08 & 7 & 2.06 \\
\hline & 17 & 0.67 & 14 & $1.68^{\star}$ \\
\hline & 4 & 1.29 & 2 & 1.90 \\
\hline & & & & \\
\hline & 22 & 0.74 & 18 & $1.95 \dagger$ \\
\hline & 1 & 0.23 & 2 & $1.37^{\circ}$ \\
\hline & 7 & 1.39 & 2 & 0.59 \\
\hline & 6 & 1.82 & 2 & $4 \cdot 88$ \\
\hline & 36 & 0.85 & 23 & $1.80 \dagger$ \\
\hline
\end{tabular}

${ }^{\star} \mathrm{p}<0.05 ; \mathrm{tp}<0.01$
TABLE VII Number of cases and relative risk of lung cancer $(R R)$, by latency time after operation and by diagnosis and type of operation

\begin{tabular}{|c|c|c|c|c|}
\hline & \multicolumn{4}{|c|}{ Latency time (years) } \\
\hline & \multicolumn{2}{|l|}{$0-19$} & \multicolumn{2}{|l|}{$20+$} \\
\hline & $\begin{array}{l}\text { No of } \\
\text { cases }\end{array}$ & $R R$ & $\begin{array}{l}\text { No of } \\
\text { cases }\end{array}$ & $R R$ \\
\hline \multicolumn{5}{|l|}{ Diagnosis: } \\
\hline Gastric ulcer & 36 & $1.56 t$ & 18 & $1 \cdot 69^{\star}$ \\
\hline Duodenal ulcer & 76 & $1.55 \ddagger$ & 49 & $1.73 \ddagger$ \\
\hline Other & 13 & $2 \cdot 00^{\star}$ & 10 & $2.63 t$ \\
\hline Operation: & & & & \\
\hline Billroth I & 86 & $\begin{array}{l}1.53 \mp \\
1.68 \star\end{array}$ & 60 & $1.97 \mp$ \\
\hline Simple suture & $\begin{array}{l}14 \\
23\end{array}$ & $2 \cdot 23 \ddagger$ & 11 & 1.75 \\
\hline Other & 2 & $0.51^{+}$ & 0 & \\
\hline Total & 125 & $1.59 \neq$ & 77 & $1.80 \ddagger$ \\
\hline
\end{tabular}

${ }^{\star} \mathrm{p}<0.05 ; \mathrm{tp}<0.01 ; \neq \mathrm{p}<0.001$

TABLE VIII Number of cases, expected numbers, and relative risk $(R R)$ of cancer at selected sites 20 years or more after operation, in selected subgroups of the cohort

\begin{tabular}{|c|c|c|c|}
\hline Site/subgroup & $\begin{array}{l}\text { No of } \\
\text { cases }\end{array}$ & $\begin{array}{l}\text { Expected } \\
\text { numbers }\end{array}$ & $R R$ \\
\hline \multicolumn{4}{|l|}{ Colorectal cancer: } \\
\hline All & 40 & $36 \cdot 24$ & $1 \cdot 10$ \\
\hline $\begin{array}{l}\text { Women } \\
\text { Billroth I }\end{array}$ & $\begin{array}{l}6 \\
3\end{array}$ & $\begin{array}{l}9 \cdot 17 \\
4 \cdot 30\end{array}$ & $\begin{array}{l}0.65 \\
0.70\end{array}$ \\
\hline Gastric ulcer & 12 & $9 \cdot 87$ & $1 \cdot 22$ \\
\hline Women+Billroth I & 1 & $1 \cdot 40$ & 0.71 \\
\hline Women + gastric ulcer & 1 & $3 \cdot 16$ & 0.32 \\
\hline Women + Billroth I+gastric & 0 & 0.67 & - \\
\hline \multicolumn{4}{|l|}{$\begin{array}{l}\text { ulcer } \\
\text { Female breast cancer: }\end{array}$} \\
\hline All & 9 & $10 \cdot 14$ & 0.89 \\
\hline Billroth II & 7 & $7 \cdot 04$ & 0.99 \\
\hline Billroth I & 0 & 1.56 & - \\
\hline Simple suture & 2 & $1 \cdot 30$ & 1.54 \\
\hline Other operations & 0 & 0.25 & - \\
\hline \multicolumn{4}{|l|}{ Gall bladder cancer: } \\
\hline $\begin{array}{l}\text { All } \\
\text { Gastric ulcer }\end{array}$ & $\begin{array}{l}1 \\
0\end{array}$ & $\begin{array}{l}2 \cdot 54 \\
0.74\end{array}$ & 0.39 \\
\hline Billroth II & 1 & 1.82 & 0.55 \\
\hline
\end{tabular}

This resembles the increased risk of gastric cancer that we reported previously in peptic ulcer patients after the initiation of medical treatment,${ }^{15}$ although the increased risk in the cohort of patients who were operated on is much less pronounced than in medically treated patients.

From five to 15 years after operation the risk of gastric cancer is significantly below the expected $(R R=0.55)$. Gastric resection inevitably implies an element of early diagnosis and treatment for gastric cancer since the surgeon will remove tissue with suspicious lesions. Furthermore, the pylorus, which most often is the site of gastric carcinomas, ${ }^{16}$ is often removed in the operation for peptic ulcer, and the patient is therefore no longer at risk from this type of gastric cancer.

The increasing trend in gastric cancer risk 15 years or more after operation is likely to be related to the operation itself. It has been shown that the concentration of $N$-nitroso compounds is increased in the gastric juice of patients operated on for peptic ulcer ${ }^{17}$ and it is an attractive hypothesis that the observed effect is the result of the carcinogenic activity of endogenously formed $N$-nitroso compounds.

The pattern of gastric cancer in the present study is in line with previous investigations. ${ }^{2-6}$ The result of the present study and the studies referred to in the Introduction are all qualitatively in agreement regarding gastric cancer risk in patients operated on for peptic ulcer.

The incidence of lung cancer is increased in the present cohort $(R R=1 \cdot 66)$. It is important to 
Relative risk $(R R)$ of gastric cancer, lung cancer, and cancer of all sites, by latency time after operation for peptic ulcer. The six estimates for gastric cancer are: $0-4$ years: 16 cases, $R R=1 \cdot 43, p=0 \cdot 10 ; 5-9$ years: six cases, $R R=0 \cdot 54$, $p=0.07 ; 10-14$ years: six cases, $R R=0.56, p=0.09$; 15-19 years: eight cases, $R R=0 \cdot 87, p=0 \cdot 43 ; 20-24$ years: 11 cases, $R R=1 \cdot 52$, $p=0 \cdot 12 ; 25+$ years: 12 cases, $R R=2 \cdot 17, p=0 \cdot 01$.

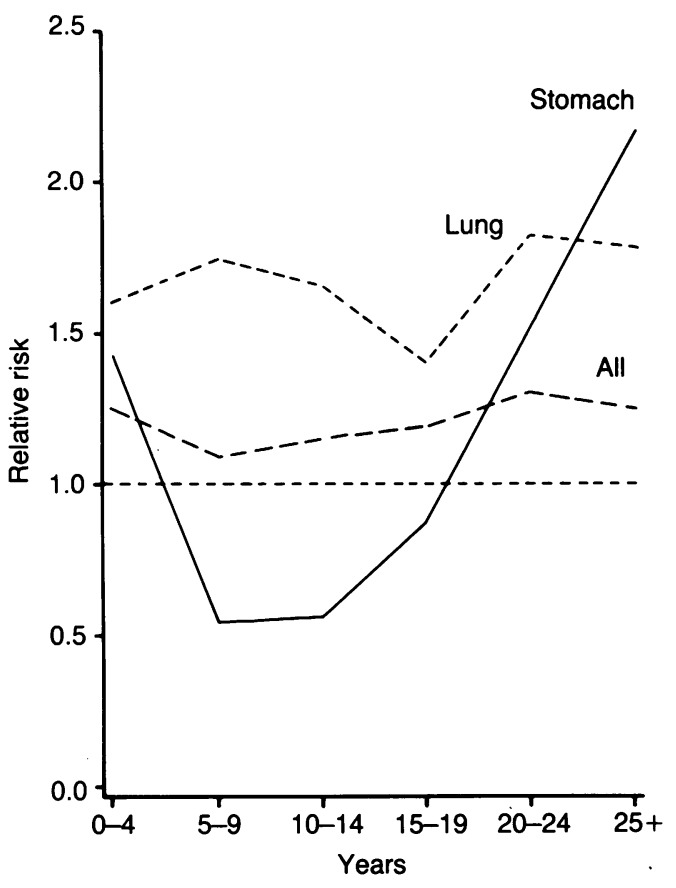

note, however, that the risk is not related to the latency time after operation but is constant over time (Figure). The most likely explanation for the association between peptic ulcer and lung cancer is the existence of a strong risk factor common to both diseases:. tobacco smoking. ${ }^{18}$ Other tobacco related cancers also occur with increased incidence, although in most cases this is not significant for specific cancer sites.

Cancers at certain other sites occurred with increased frequency in the British study 20 years or more after operation (colon and rectum, biliary tract, female breast, pancreas, oesophagus, bladder). ${ }^{5-8}$ The present study finds no significant excess incidence for cancer at these sites. The estimated relative risks from the British study ranged from 1.6 (colorectal cancer) to 8.6 (biliary tract). ${ }^{5}$ In the present study the highest of these point estimates is 1.5 for pancreatic cancer.

Analyses of the British study have identified subgroups of that series of patients with especially increased mortality from specific cancers. ${ }^{5-8}$ Twenty years or more after an ulcer operation an increased risk of colorectal cancer was confined to the subgroup of women who had a Billroth I operation for gastric ulcer, ${ }^{7}$ and the highest mortality from breast cancer was seen in the subgroup of women who had a vagotomy. The excess of deaths from biliary tract cancer was most pronounced in gastric ulcer patients and in those who had had a Billroth II operation. ${ }^{8}$

These specific associations are explored in Table VIII. For colorectal cancer there is no indication of increased risk being associated with the female sex, the Billroth I operation, or gastric ulcer, independently or in combination. The relative risk of breast cancer after vagotomy, reported to be 10 -fold, ${ }^{7}$ cannot be evaluated in the present study due to the low proportion of vagotomies. Among those having a Billroth I or II resection, however, the increase in relative risk of breast cancer reported from Britain (five cases; $\mathrm{RR}=3 \cdot 1 ; \mathrm{p}<0.05$ ) is not supported by our data. Cancer of the gall bladder was reported to occur 10-fold in gastric ulcer patients and in those having a Billroth II operation in the British series. ${ }^{8}$ The Danish data do not show any indication of excessive risk in these groups.

For the subgroups presented in Table VIII we have compared the expected number of cancer cases in our own investigation with the expected number of deaths reported in publications from the British study. ${ }^{58}$ The expected number, in all cases where comparison is possible, is higher (and most often substantially so) in the Danish study than in the British study. Inadequacy of study size hence cannot explain our failure to support the associations proposed by subgroup analyses of the British data set. The only exception to this is the association between vagotomy and female breast cancer which cannot be evaluated in the Danish data set.

The present results do not support the hypothesis that surgery for peptic ulcer is associated with a generally increased cancer risk at a multitude of sites, nor do they support excessive cancer risk being associated with surgery for peptic ulcer in the subgroups proposed by Caygill et al..$^{5-8}$ Apart from gastric cancer and tobacco related cancers (discussed above) there seems to be no excess cancer risk after gastrectomy.

Caygill et al do not report results for nonHodgkin lymphomas. ${ }^{5}$ The increase in nonHodgkin lymphomas in the present cohort may be a chance occurrence.

The members of the present cohort were ulcer patients who lived in the western part of Denmark. Cancer incidence in the cohort has been compared to the cancer incidence in the country as a whole. Compared to the overall rates for Denmark, relative risks in western Denmark for various sites in the 1970 s were: all sites 0.90 , buccal cavity and pharynx 0.83 , oesophagus 0.89 , stomach 1.03 , colon 0.89 , rectum 0.97 , gall bladder 0.89 , pancreas 0.86 , lung 0.74 , female breast 0.93 , prostate 0.93 , and bladder $0 \cdot 77$. $^{19}$ For stomach cancer the use of national rates does not affect the magnitude of the relative risk, while the relative risk of cancers related to smoking have probably been underestimated by some $10-25 \%$ overall. The trend in relative risk is not influenced by the use of national incidence rates. For most other sites the error in estimated relative risks is within $10 \%$, and the use of national rates without geographic adjustment cannot explain the discrepancy between the British study ${ }^{5}$ and the present study.

The present study, with virtually complete follow up and independent ascertainment of incident cases of cancer, supports the hypothesis that surgical treatment for peptic ulcer induces carcinogenic processes which act locally on the remaining gastric mucosa, but our data do not support the idea that partial gastrectomy is causally associated with an increased risk of other malignancies.

1 Fischer $\mathrm{AB}$. The long-term results following Billroth II resection for duodenal ulcer. Dan Med Bull 1986; 33: 31935 .

2 Viste A, Biørnestad E, Opheim P, et al. Risk of carcinoma following gastric operations for benign disease: a historical colowing gastric operations for benign disease: a his.

3 Lundegårdh G, Adami HO, Helmick C, Zack M, Meirik O. Stomach cancer after partial gastrectomy for benign ulcer Stomach cancer after partial gastrectomy for
disease. NEngl f Med 1988; 319: 195-200. 
4 Arnthorsson G, Tulinius H, Egilsson V, Sigvaldason $H$, Magnusson B, Thorarinsson $\mathrm{H}$. Gastric cancer after gastrec tomy. Int 7 Cancer 1988; 42: 365-7.

5 Caygill CPJ, Hill MJ, Hall CN, Kirkham JS, Northfield TC. Increased risk of cancer at multiple sites after gastric surgery Increased risk of cancer at multiple sites

6 Caygill CPJ, Hill MJ, Kirkham JS, Northfield TC. Mortality from gastric cancer following gastric surgery for peptic ulcer. Lancet 1986; i: 929-31.

7 Caygill CPJ, Hill MJ, Kirkham JS, Northfield TC. Mortality from colorectal and breast cancer in gastric-surgery patients. Int $\mathcal{F}$ Colorectal Dis 1988; 3: 144-8.

8 Caygill C, Hill M, Kirkham J, Northfield TC. Increased risk of biliary tract cancer following gastric surgery. $\mathrm{Br} \mathcal{F} \mathrm{Cancer}$ 1988; 57: 434-6.

9 Correa P. A human model of gastric carcinogenesis. Cancer Res 1988; 48: 3554-60.

10 Mirvish SS. The etiology of gastric cancer. Intragastric nitrosamide formation and other theories. F Natl Cancer Inst 1983; 71: 629-47.

11 Toftgaard C. Risk of colorectal cancer after surgery for benign peptic ulceration. BrF Surg 1987; 74: 573-5.
12 Toftgaard C. The overall cancer incidence after peptic ulcer surgery. A prospective cohort study. Cancer fournal 1988; 2: $17-20$.

13 Toftgaard C. Gastric cancer after peptic ulcer surgery: historic prospective cohort investigation. Ann Surg 1989; 210: 159-64.

14 Danish Cancer Society. Cancer incidence in Denmark 1986 Copenhagen: Danish Cancer Society. Danish Cancer Regis-

try, 1989 .
15 Møller H, Lindvig K, Klefter R, Mosbech J, Jensen OM. Cancer occurrence in a cohort of patients treated with cimetidine.Gut 1989; 30: 1558-62.

16 Møller H, Jensen OM. Temporal trends in incidence of cance of oesophagus, cardia, and stomach in Denmark, 19431982. Ugeskr Laeger 1987; 149: 1904-9.

17 Reed PI, Smith PLR, Haines K, House FR, Walters CL Gastric juice $\mathrm{N}$-nitrosamines in health and gastroduodenal disease. Lancet 1981; ii: 550-2.

18 Anonymous. Smoking and health. Publication no 1103. Washington DC: Public Health Service, 1964.

19 Carstensen B, Jensen OM. Atlas of cancer incidence in Denmark 1970-79. Copenhagen: Danish Cancer Society, 1986. 